\title{
Exposure to Lateral Collision in Signalized Intersections with Protected Left Turn under Different Traffic Control Strategies
}

\author{
Sophie Midenet ${ }^{\mathrm{a}}$, Nicolas Saunier ${ }^{\mathrm{b}, *}$, Florence Boillot $^{\mathrm{c}}$ \\ ${ }^{a}$ Université Paris-Est, IFSTTAR, GRETTIA, 2 rue de la Butte Verte, 93166 Noisy-le-Grand cedex, France \\ ${ }^{b}$ École Polytechnique de Montréal, C.P. 6079, succ. Centre-ville, H3C 3A7, Montréal Québec, Canada \\ ${ }^{c}$ Université Paris-Est, IFSTTAR, GRETTIA, 25 Allée des Marronniers, 78000 Versailles, France
}

\begin{abstract}
This paper proposes an original definition of the exposure to lateral collision in signalized intersections and discusses the results of a real world experiment. This exposure is defined as the duration of situations where the stream that is given the right-of-way goes through the conflict zone while road users are waiting in the cross-traffic approach. This measure, obtained from video sensors, makes it possible to compare different operating conditions such as different traffic signal strategies. The data from a real world experiment is used, where the adaptive real-time strategy CRONOS (ContRol Of Networks by Optimization of Switchovers) and a time-plan strategy with vehicle-actuated ranges alternately controlled an isolated intersection near Paris. Hourly samples with similar traffic volumes are compared and the exposure to lateral collision is different in various areas of the intersection and various traffic conditions for the two strategies. The total exposure under peak hour traffic conditions drops by roughly 5 min per hour with the CRONOS strategy compared to the time-plan strategy, which occurs mostly on entry streams. The results are analyzed through the decomposition of cycles in phase sequences and recommendations are made for traffic control strategies.
\end{abstract}

Keywords: Exposure to Lateral Collision, Signalized Intersection, Traffic Control Strategy, Adaptive Real-time Strategy

\section{Introduction}

Over the years, there has been considerable interest in improving signalized intersection control to minimize delays and stops. It has become possible to develop traffic control strategies that can adapt to current traffic conditions in real-time thanks to the advancement of sensors. However little is known about the impact on safety of traffic control strategies, particularly adaptive ones. This paper proposes an original measure of exposure to lateral collisions and evaluates the impact on this exposure of the real-time adaptive traffic control strategy CRONOS. This traffic control strategy - CRONOS stands for ContRol Of Networks by Optimization of Switchovers was developed in the 1990s (Boillot et al., 2006) and relies on video sensors that provide queue lengths and spatial occupancy rates every second (Aubert et al., 1996). Its algorithm controls the traffic lights in order to minimize total delay over a shortrange time horizon. The CRONOS strategy was compared to a standard time-plan based control strategy with vehicle-actuated ranges during a real world experiment. The comparisons between strategies in terms of fluidity criteria and environmental impacts have been published previously (Midenet et al., 2004; Boillot et al., 2006). The present paper deals with a safety comparison.

\footnotetext{
${ }^{*}$ Corresponding author. Tel.: +1 5143404711 (ext. 4962); fax: +1 514340 3981.

Email addresses: sophie.midenet@ifsttar.fr (Sophie Midenet), nicolas.saunier@polymtl.ca (Nicolas Saunier), florence.boillot@ifsttar.fr (Florence Boillot)
}

We introduce an original model to evaluate the exposure to lateral collision in intersections. Our model considers the conditions in which road users go through an intersection with respect to the presence of road users in cross-traffic approaches. An exposure measure is defined that can be automatically estimated from the occupancy data provided by the video sensors. The traffic databases recorded during the CRONOS strategy assessment enable us to obtain quantitative results in a real world setting and to compare the exposure between strategies and between traffic volume conditions.

The next section reviews the methods for road safety analysis in signalized intersections. Section 3 presents our model of road users' exposure to lateral collision in an intersection. Section 4 describes the experimental site and the data. Section 5 presents the experimental results which are discussed in Section 6.

\section{Safety Analysis in Signalized Intersections}

\subsection{Safety in Signalized Intersections}

The definition of safety used in this work is the number of collisions expected to occur at a given location per unit of time, where "expected" refers to "the average in the long run if it were possible to freeze all prevailing conditions that affect safety" (Hauer et al., 1988). Road safety analysis relies traditionally on historical collision data, and its relationship with traffic and roadway characteristics. Some safety performance models provide insights into the causes of collisions in signalized intersections, as they include characteristics of signal control. Greibe 
(2003) showed that single and rear-end collisions are more frequent in signalized junctions whereas lateral collisions are more frequent in non-signalized ones. Sebastian (1999) addressed left-turn phasing types and showed the positive effect of protected phasing on 142 intersections; the difference according to the type of control strategy (semi-actuated or pre-timed) was not found to be significant. Studies on 52 four-legged intersections in Singapore (Chin and Quddus, 2003; Mitra et al., 2002) showed a negative effect of a high number of phases, and a slightly positive effect of adaptive versus pre-timed strategies. Focusing on left-turn crashes at 200 signalized intersections in Florida, Wang and Abdel-Aty (2008) found that protected leftturn signal and longer all-red time decrease injury severity.

Proactive methods aim to address the limitations of collision data (Sayed and Zein, 1999; Saunier et al., 2010): they rely on more frequent safety-related traffic events to estimate surrogate safety measures. Traffic conflicts have received the most attention and are defined as "observational situation(s) in which two or more road users approach each other in space and time to such an extent that a collision is imminent if their movements remain unchanged" (Amundsen and Hydén, 1977). Svensson and Hydén (2006) used traffic conflict techniques (Hydén, 1987) and showed that the distribution of the severity of conflicts is different in signalized and non-signalized intersections. Other approaches study conditions known to favour the occurrence of collisions, such as red-light running (Midenet, 2005).

\subsection{Exposure to Collision}

The concept of exposure has been introduced to "take account of the amount of opportunity for collisions which the driver of the traffic system experiences" (Chapman, 1973). Archer (2004) defines exposure as a "measure of spatial or temporal duration in the traffic system in relation to the number of dynamic system objects, road users, vehicles, etc". In its most general definition, any necessary situation for a collision to occur can be considered as exposure to a road collision. Exposure is used to compute collision rates $\tau_{E}=N_{C} / E$ defined for a given period of time during which $N_{C}$ collisions were observed and exposure was measured as $E$. The collision rate can be considered as the conditional probability of collision for each unit of exposure (Chapman, 1973) and it depends in the general case on this very exposure. The relationship of safety, measured by $N_{C}$, to exposure is therefore complex. Nevertheless, experimental studies, using traffic volumes as exposure, show that safety is a monotonically increasing function of exposure (Hauer et al., 1988; Ardekani et al., 2001). Exposure control is consequently one of the existing strategies to improve safety.

\subsection{Exposure to Collision in a Signalized Intersection}

Traffic volumes are the most common measure of exposure in intersections and can be derived from known aggregate measures such as hourly directional traffic volumes (Qin et al., 2006; Zhang et al., 2006) or annual average daily traffic (Elvik et al., 2009). Yet, through simple models, they only measure the presence of road users on the road for a given period of time, not their actual simultaneous occurrence: this is a necessary condition for collisions to occur, but with a tenuous connection to collisions. A better measure of exposure should take into account the way road users go through an intersection with respect to other road users with which they could be involved in an interaction that could lead to a collision.

The presence of road users on the cross-traffic approach is a necessary condition to the occurrence of a lateral collision in the conflict zone: when a road user is crossing the conflict zone, there is a chance of lateral collision only if there is at least one road user in the cross-traffic approach. This situation is called a critical situation for lateral collisions and constitutes an eventbased measure of exposure to lateral collision. In signalized intersections, red-light running is a second necessary condition for a collision to happen in the conflict zone. However, the relationship between critical situations and red-light running is complex and will not be investigated in this paper.

This paper investigates the impact of signal control on the occurrences of critical situations. It deals only with exposure to lateral collision and no other type.

\section{Method to Measure and Compare Exposure to Lateral Collision}

The exposure to lateral collision for signalized intersections is defined as the temporal duration of critical situations, which occur when the stream that is given right-of-way by the signal goes through the conflict zone while there is at least one road user in the cross-traffic approach. Let us consider a signalized intersection of two one-way roads denoted A and B (see Figure 1), and a given period $T$ with cumulated traffic volumes $V(A)$ and $V(B)$. Duration $Z(A)$ is the cumulated amount of time during which road users of stream $\mathrm{A}$ are crossing the conflict zone within period $T: Z(A)$ is split between exposed flow $Y(A)$ when road users are present in B and non-exposed flow $X(A)$ otherwise.

$Y(A)$ can be further sub-divided by considering whether all the close road users in B - the closest in each lane - are stationary or at least one close road user is moving in B. $Y_{m}(A)$ is the cumulated amount of time during which road users of stream $\mathrm{A}$ are crossing the conflict zone when at least one close road user is moving in B. This situation is closer to a conflict than when all road users in B are stationary, and thus closer to the occurrence of a collision. The definitions are symmetric with respect to $\mathrm{A}$ and $\mathrm{B}$, and are discussed without mentioning the origin of the stream.

The time period $T$ for integration of the data samples is one hour. One-hour samples are large enough to ensure homogeneous and stable conditions and short enough to guarantee the independence of traffic volumes from traffic control strategies (Midenet et al., 2004; Boillot et al., 2006). If there is no red light violation, $Z$ is inferior or equal to the sum of green and intergreen (yellow plus all red) periods.

All these durations depend strongly on the speed of the vehicles going through the intersection: the slower the vehicle, the more time it spends in the conflict zone, and the more it contributes to the corresponding durations. The split between 

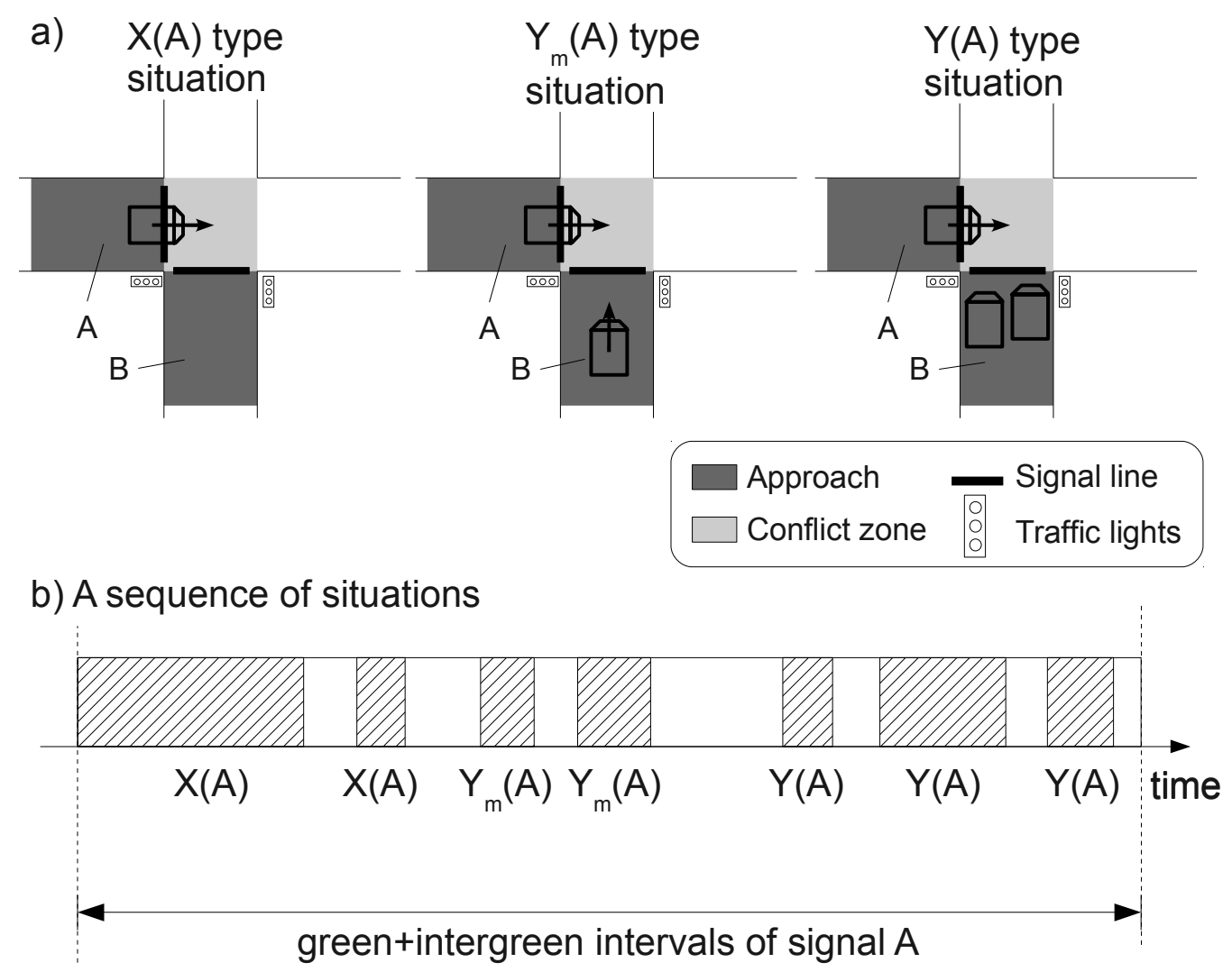

Figure 1: The typical situations for exposure to lateral collision for road users coming from stream A: a) the different crossing situations; b) an example of a sequence of situations.

$X$ and $Y$ is strongly connected with the situation occurring at onsets of the green signal. There are usually no road users in the cross-traffic approach at the onset of the green signal, so the first instants of $Z$ within the cycle count as $X$. As soon as the first road user enters the cross-traffic approach, it becomes $Y$. Any split of $Z$ into $X$ and $Y$ is possible between the extreme situations $Z=X$ and $Z=Y$; figure 1 shows an example.

In our context, the traffic volume can be considered as a measure of the intensity of use of the intersection, and it should be equalized between samples to be compared (Hauer, 1995). Hourly measures of $Y$ are used to compare different operating conditions with similar hourly traffic volumes on both approaches. Even if the relation between the traffic volume and the exposure is complex and non-linear, the ratio $Y / V$ becomes relevant within hourly sample datasets with similar traffic volumes to take into account the remaining entry volume differences. Volume-normalized measures of exposure are defined by $Z_{V}=Z \times \frac{\bar{V}}{V}, Y_{V}=Y \times \frac{\bar{V}}{V}$ and $X_{V}=X \times \frac{\bar{V}}{V}$, where $\bar{V}$ is the mean hourly volume of the stream for the set of samples.

\section{The Experimental Site and Data}

Measures of exposure are obtained through a vehicle interaction analysis system connected to an experimental site. This site is an isolated signalized intersection in the close suburbs of Paris composed of four sub-intersections (see Figure 2).
Based on video sensors and communication devices linked to the traffic signal controller, the experimental system enables us to send second-by-second traffic signal state commands to the controller, and to record and replay traffic scenes on the basis of second-by-second traffic measures.

\subsection{Detection of Critical Situations}

The vehicle interaction analysis system processes spatial occupancy measurements provided by the video sensors. As illustrated in Figure 3, the spatial occupancy information is distributed on a grid of spatial units whose state represent the dynamics of the road users over one second. A rule-based system has been developed to detect groups of moving roads users and to identify critical situations. Durations $Z, X, Y$ and $Y_{m}$ are updated every second depending on the detected situation.

The detection of $Y$ and $Y_{m}$ situations was evaluated for two sub-intersections and four incoming streams. The system proves reliable: the mean precision and recall performance measures are respectively $86 \%$ and $91 \%$ for $Y$ (minima $77 \%$ for both), and $77 \%$ and $85 \%$ for $Y_{m}$ (minima $74 \%$ and $76 \%$ ) (see (Saunier and Midenet, 2010) for more details).

\subsection{Database Constitution}

A real world experiment was undertaken in 1998 and 1999 in order to assess the adaptive real-time control strategy CRONOS. The aim was to compare the CRONOS strategy with 


\section{ב-- Pedestrian crossing line}

__ Vehicle signal line

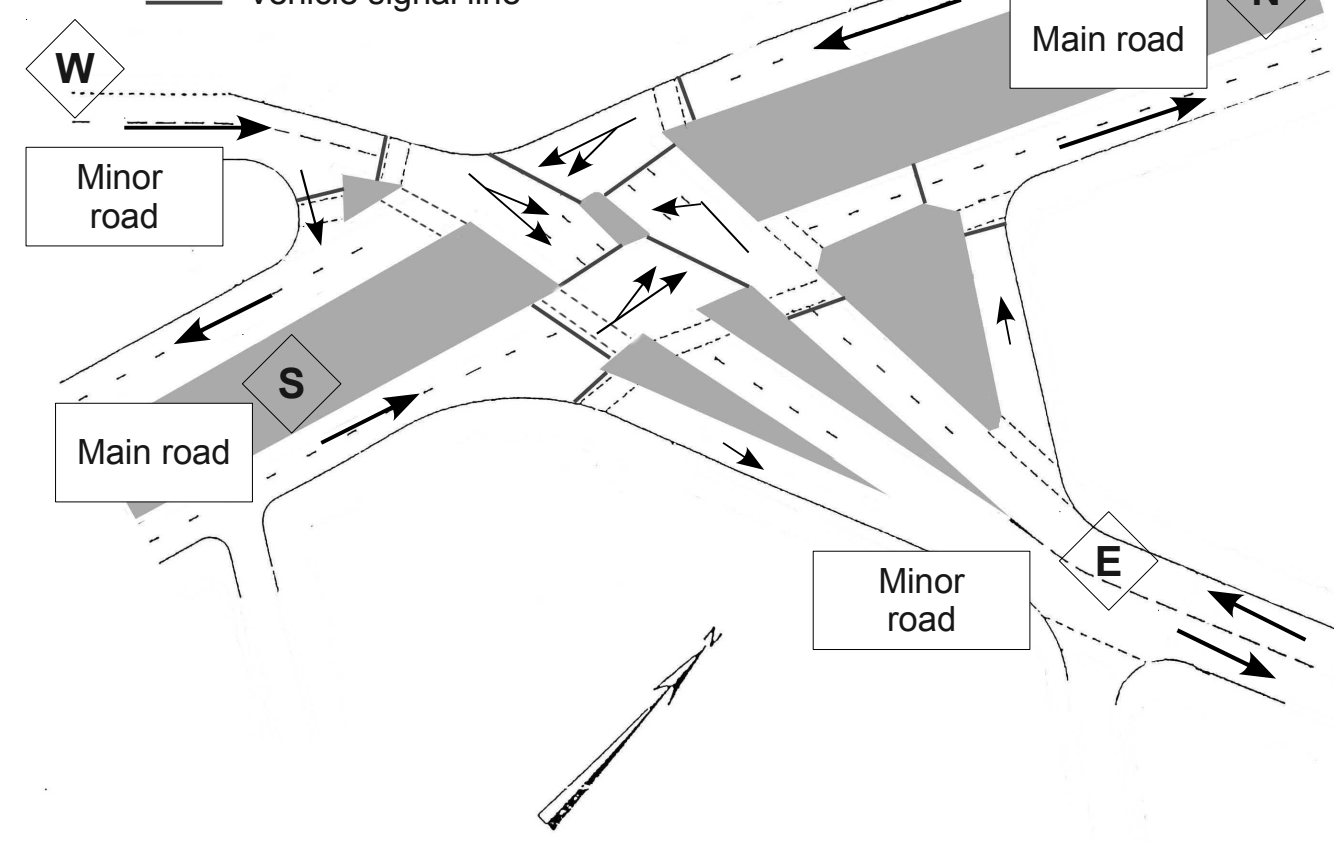

Figure 2: The experimental site.
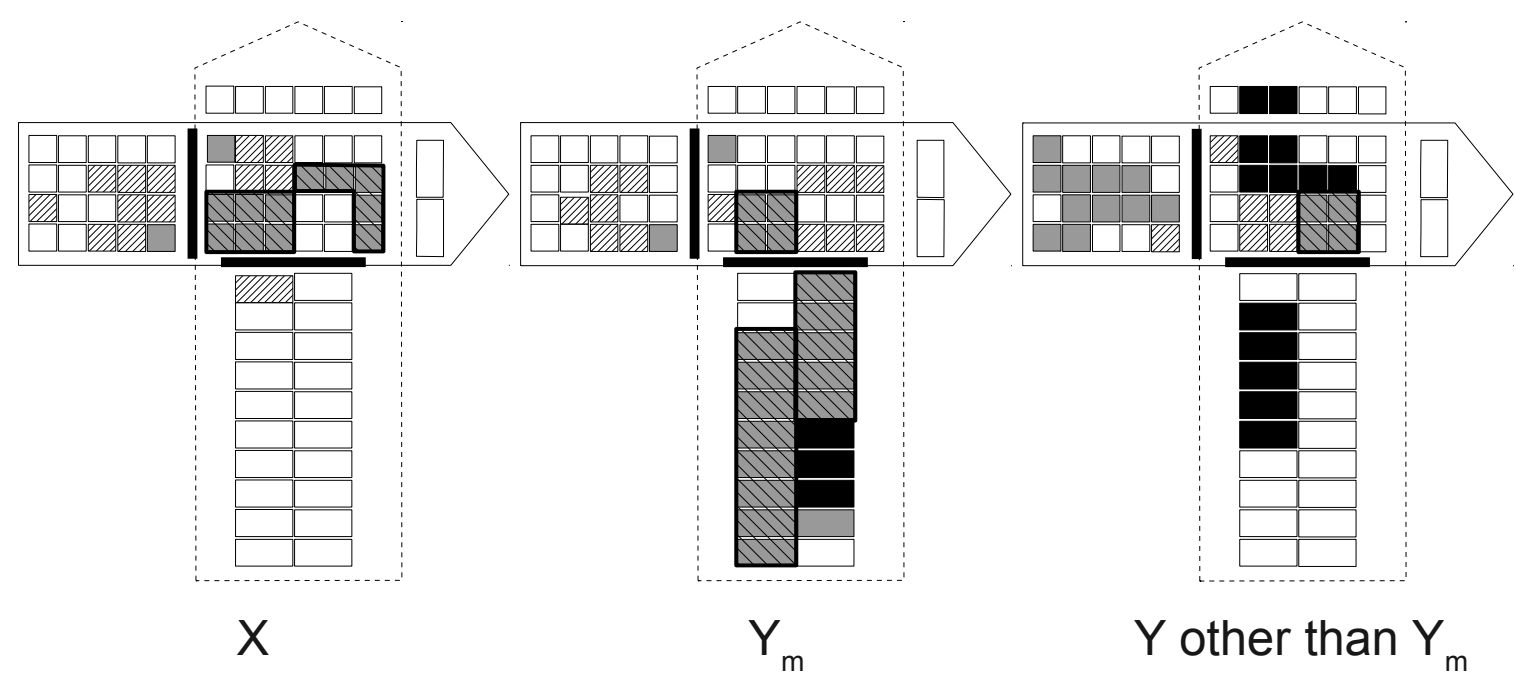

Occupancy Information

Emptiness

Moving presence

End of presence

Droup of moving road users

- Signal line

Direction of traffic flow

Stationary presence

Approach with the green light

Figure 3: Examples of the data collected and the detection of critical situations. 
a time plan strategy with vehicle-actuated ranges, called here the baseline strategy (called the L-STRAT strategy in (Boillot et al., 2006)). Half-day recordings have been collected over several months during weekdays between 08:00 and 18:30, while one of the two control strategies was controlling the intersection. Each record was split into fixed hourly windows, from [08:00, 09:00] to [17:30, 18:30]. Using estimated total crossing hourly volumes, we defined several classes of traffic conditions. Further details on this experiment can be found in (Midenet et al., 2004; Boillot et al., 2006).

Looking for situations with statistical differences in terms of exposure to lateral collision, we selected two groups of contrasting traffic conditions: peak hours traffic and fluid traffic. The same time-windows were used for homogeneity in terms of crossing movement: [08:00, 09:00] for peak traffic (P) and [10:00, 11:00] for fluid traffic (F). Hourly volumes per stream for each of the four conflict zones were taken into account for sample selection: outliers were discarded to ensure that the relative difference in mean hourly volume between the two strategies does not exceed $6 \%$ for each traffic condition. Our final dataset includes at least 5 hourly samples for each pair of traffic condition and control strategy, which amounts to a minimum of 20 hours of traffic scenes for each conflict zone.

\subsection{Infrastructure and Traffic Volume}

The experimental site is made up of four double-lane entry approaches and three double-lane outbound legs. The inner area includes four conflict zones and four storage zones for leftturning vehicles. Entry approaches and inner storage zones are controlled by traffic signals; inner storage zones are about $10 \mathrm{~m}$ long. The traffic signals are called entry signals $(\mathrm{N}, \mathrm{S}, \mathrm{E}$ and $\mathrm{W}$ on Figure 4) or inner signals (n, s, e and w on Figure 4). Since right-turning vehicles have special links and do not cross the intersection, they are not considered in our study. The main road runs North-South and links Paris to the southern suburbs with high volumes of transit traffic at peak hours. The minor road runs East-West and concerns local traffic with lower volumes. The U-turn volumes are significant along the North-South road. The total traffic is split up into eight crossing movements, denoted by the origin-destinations in square brackets. Manual vehicle counts were carried out thanks to the video recordings and yielded estimations of the mean hourly volumes (see Table 1).

For safety reasons and considering the high speed profile on the main road, the control strategies operating on the intersection have to respect the following constraint: an entry signal always turns yellow before the inner signal immediately following does. For instance signal $\mathrm{N}$ always turns yellow before signal $\mathrm{n}$ does. As a consequence, turning movements are the only movements that can feed into the inner storage zones, except in congestion or queue spillback situations. Naming storage inner zones the same way as the corresponding signal, storage zones $\mathrm{w}, \mathrm{s}, \mathrm{e}$ and $\mathrm{n}$ are fed respectively by the movements ([NE] + $[\mathrm{NN}]),([\mathrm{WN}]+[\mathrm{NN}]),([\mathrm{SS}])$ and $([\mathrm{ES}]+[\mathrm{SS}])($ see Table 2$)$.

\subsection{The Phasing of the Control Strategies}

Storage management and transitions between phases play a key role in our perspective, as they are strongly related to the way $Z$ duration divides up into $Y$ or $X$ durations. The challenge comes from the CRONOS strategy which relies on a real-time optimization module without any pre-defined stage; it looks for the best signal state sequence to apply for the next time steps, considering the set of safety constraints and the objective of reducing total delay.

The Highway Capacity Manual (Transportation Research Board, 2000) defines an interval as a period of time during which all signal states remain constant, and a phase as the part of a cycle allocated to any combination of movements receiving the right-of-way simultaneously during one or more intervals. We define an $\mathcal{E}$-phase ( $\mathcal{E}$ for entry) as the part of a cycle allocated to any combination of entry streams allowed to enter simultaneously during one or more intervals. Inner signal states may vary during an $\mathcal{E}$-phase. Possible $\mathcal{E}$-phases in our intersection are the following:

- $\mathrm{S}$ and $\mathrm{N}$ simultaneously; this $\mathcal{E}$-phase is called $\Phi_{1}$

- E and W simultaneously; this $\mathcal{E}$-phase is called $\Phi_{2}$

- either S, N, E or W alone

- no entry stream allowed to enter: all red entry period

Two additional constraints for control strategies have been identified on this intersection by local traffic engineers: every entry stream has to be given a green period at each cycle (no phase skipping), and each cycle has to include an interval for a reference green state. This state, called RefG state, is defined by entry signals $\mathrm{N}$ and $\mathrm{S}$ and inner signals $\mathrm{n}$ and $\mathrm{s}$ in the green state; it occurs during $\mathcal{E}$-phase $\Phi_{1}$. The cycle of the intersection can then be defined as the period between a RefG state onset and the next one. The opening offsets between the eight signals ( $\mathrm{nN}, \mathrm{nS}, \mathrm{sS}, \mathrm{sN}, \mathrm{eE}, \mathrm{eW}, \mathrm{wW}$ and $\mathrm{wE}$ ) fully describe the phasing sequence of a cycle. The words "opening" and "closing" are used to denote respectively the green onset and the red onset.

We extracted a cycle database from the traffic scene database by selecting the same hourly windows from 8:00 to 11:00 with equal distribution between the two strategies. The two sets of cycles, comprising 1064 samples for the baseline strategy and 1210 samples for the CRONOS strategy, were analyzed through agglomerative hierarchical clustering, using the Euclidean distance on scaled and centred data, and the Ward criteria.

The resulting clusters, called regimes, are presented in Table 3. Each regime is described as a sequence of $\mathcal{E}$-phases and transitions that occur starting from the RefG state onset. We distinguish a full $\mathcal{E}$-phase from a transition on the basis of the duration distribution; median threshold is set to $6 \mathrm{~s}$ for all red periods and $5 \mathrm{~s}$ for the other $\mathcal{E}$-phases. Only predominant transitions are shown in Table 3 , which usually stand for more than $80 \%$ of the whole cluster. $\Phi_{1}$ and $\Phi_{2}$ are present in every regime except one with the CRONOS strategy where $\Phi_{2}$ is split into two full $\mathcal{E}$-phases; this regime is called " $\mathrm{Cr} \_3$ st" for "three stages". The CRONOS strategy also creates two regimes with a full $\mathrm{S} \mathcal{E}$-phase, and two regimes with long all red transition periods. The predominant regime in both traffic conditions is a $\Phi_{1}-\Phi_{2}$ sequence with very short transitions; it is called $\mathrm{Cr}_{-} 0$. 




Figure 4: The intersection schema with differences in exposed flow duration.

Table 1: Hourly volumes for each entry and each movement (mean and standard deviation).

The measures are obtained from eight 20 -min sequences with four sequences per traffic condition.

\begin{tabular}{|c|c|c|c|c|c|c|c|}
\hline \multicolumn{8}{|c|}{ Peak hour traffic $(\mathrm{P})$} \\
\hline Entry $S$ & & Entry N & & & Entry E & Entry W & \\
\hline $\begin{array}{l}1190 \pm 77 \\
{[S N]}\end{array}$ & {$[S S$} & $\begin{array}{l}653 \pm 29 \\
{[N S]}\end{array}$ & [NE] & {$[\mathrm{NN}]$} & $\begin{array}{l}383 \pm 41 \\
{[E S]}\end{array}$ & $\begin{array}{l}265 \pm 16 \\
{[\mathrm{WE}]}\end{array}$ & {$[\mathrm{WN}]$} \\
\hline $1121 \pm 72$ & $69 \pm 9$ & $557 \pm 29$ & $68 \pm 5$ & $29 \pm 4$ & $383 \pm 41$ & $146 \pm 7$ & $119 \pm 13$ \\
\hline \multicolumn{8}{|c|}{ Fluid traffic $(\mathrm{F})$} \\
\hline Entry $\mathrm{S}$ & & Entry N & & & Entry E & Entry W & \\
\hline $578 \pm 47$ & & $445 \pm 26$ & & & $153 \pm 9$ & $93 \pm 7$ & \\
\hline$[\mathrm{SN}]$ & [SS] & [NS] & {$[\mathrm{NE}]$} & {$[\mathrm{NN}]$} & [ES] & [WE] & {$[\mathrm{WN}]$} \\
\hline $536 \pm 41$ & $41 \pm 9$ & $351 \pm 26$ & $63 \pm 6$ & $31 \pm 5$ & $153 \pm 9$ & $53 \pm 5$ & $40 \pm 7$ \\
\hline
\end{tabular}

Table 2: Potential hourly supply to inner storage zones.

\begin{tabular}{lllll}
\hline Traffic & Storage $\mathrm{n}$ & Storage $\mathrm{s}$ & Storage $\mathrm{w}$ & Storage e \\
Condition & {$[\mathrm{ES}]+[\mathrm{SS}]$} & {$[\mathrm{WN}]+[\mathrm{NN}]$} & {$[\mathrm{NE}]+[\mathrm{NN}]$} & {$[\mathrm{SS}]$} \\
\hline $\mathrm{P}$ & $383+69=452$ & $119+29=148$ & $68+29=97$ & 69 \\
$\mathrm{~F}$ & $153+41=194$ & $40+31=71$ & $63+31=94$ & 41 \\
\hline
\end{tabular}


The baseline strategy provides much fewer degrees of freedom since closing offsets $\mathrm{Nn}$, Ee, Ss and Ww are fixed (10 s, $4 \mathrm{~s}, 3 \mathrm{~s}$ and $4 \mathrm{~s}$ respectively), and so are the opening offsets $\mathrm{eW}, \mathrm{sN}, \mathrm{wE}$ and $\mathrm{nS}$. The clustering reveals two regimes, including a full $\mathrm{S}$ $\mathcal{E}$-phase that occurs mainly in peak traffic conditions.

\section{Experimental Results: Comparison of Exposure}

\subsection{Exposure for the Baseline and CRONOS Strategies}

Durations $Z$ and $Y$ for the baseline strategy reflect the influence of stream volumes (see Table 4): $Z$ and $Y$ are higher in peak traffic conditions than in fluid traffic conditions, higher for main road streams ( $\mathrm{S}, \mathrm{N}, \mathrm{s}$ and $\mathrm{n}$ ) than for minor road streams, and higher for inner streams than for entry streams. Streams $\mathrm{S}, \mathrm{s}$ and e produce the highest durations $Y$ whatever the traffic conditions. Duration $Y_{m}$ reaches a high level on entry stream $\mathrm{S}$ and represents more than $50 \%$ of the total duration $Y$.

The two sets of hourly samples are compared using the nonparametric Wilcoxon rank sum test suited to non Gaussian scarce data. As depicted in Table 5, the hourly volumes for the inner streams $\mathrm{n}$ and e are slightly lower for the CRONOS strategy sample in peak hour conditions. The biggest differences in $Z$ and $Z_{V}$ take place at inner stream e with around two additional minutes of flow for the CRONOS strategy. The number of significant duration differences increases when $Y$ and $Y_{V}$ are considered. For the entry streams, important savings on $Y_{V}$ are achieved when the CRONOS strategy is used on entry $\mathrm{S}$, entry $\mathrm{E}$ (peak) and more lightly on entry $\mathrm{W}$ (fluid). These benefits correspond to large increases in duration $X$, meaning that the CRONOS strategy partly converts some exposed flow into unexposed flow. The ratio $Y / Z$ decreases from between $10 \%$ and $18 \%$ on these streams. As for the inner streams, four out of eight volume-normalized differences are significant, with smaller differences than for the entry streams. In stream $s$, the CRONOS strategy saves more than one minute of exposed flow duration in both traffic conditions. On the other hand two inner streams in fluid conditions, $\mathrm{n}$ and e, show slight $Y_{V}$ benefits for the baseline strategy, along with a $Z_{V}$ increase. Differences in $Y_{m}$ are small and not significant except on entry stream $\mathrm{S}$. The absolute difference in $Y_{m}$ on stream $\mathrm{S}$ is roughly equal to the absolute difference in $Y$, meaning that the benefit in $Y$ is achieved through a $Y_{m}$ decrease. The differences in volume-normalized exposed flow durations are indicated in Figure 4.

\subsection{Entry Streams}

On entry approaches, queues almost always occur during the red period; thus there are always some vehicles ready to flow at the green onset. The conditions that favour unexposed flow for the entry thus depend on the way the conflicting cross-traffic inner storage zone is supplied when the entry stream begins to flow. The key points are the size of the movements that supply the zone and the opening offsets between the signals that control these movements. In the notation of offsets, $O($.$) and$ $C$ (.) designate respectively the onset of the green signal and the onset of the red signal.

\subsubsection{Main Road: Streams $N$ and $S$}

The inner storage zones $\mathrm{w}$ and e are only fed by the leftturning movements from the opposite entries $\mathrm{N}$ and $\mathrm{S}$ respectively; the extent of these movements is given in Table 2. The opening offsets $O(S) O(N)$ are depicted in Figure 5. With the baseline strategy, entry signal $\mathrm{N}$ opens $5 \mathrm{~s}$ before signal $\mathrm{S}$ : the offset exceeds $4 \mathrm{~s}$ in three quarters of the total cycles. The storage zone $\mathrm{w}$ is supplied with a left-turning movement which is high even in fluid conditions. Due to the $5 \mathrm{~s}$ offset, the supply of inner storage zone $w$ begins during the queue discharge of stream S, inducing high $Y$ and $Y_{m}$ levels. The opening offset is more favourable with the CRONOS strategy: the regime Cr_3st (11\% of all cycles) is the only one during which $\mathrm{N}$ opens clearly before $\mathrm{S}$, otherwise $\mathrm{N}$ opens at the same time as or after S.

This 5 s opening offset does not favour the baseline strategy on the opposite entry N. The whole entry stream E stops at signal $\mathrm{n}$; the opening offset between $\mathrm{E}$ and $\mathrm{W}$ (5 s as median) is not sufficient for stream $E$ to clear the intersection. In peak hour condition, hourly volume of stream E exceeds the storage zone capacity of zone $n$; in many cycles a few vehicles behind inner signal e are caught by red signal onset when entry stream $\mathrm{N}$ begins to flow. This situation prevents stream $\mathrm{N}$ from producing unexposed flow. With the CRONOS strategy, three regimes (36\%) allow the part of stream $\mathrm{E}$ that enters the intersection to clear it: $\mathrm{Cr} \_\mathrm{AR} 2, \mathrm{Cr} \_\mathrm{S} 2$ and $\mathrm{Cr}_{-} 3$ st. In fluid traffic conditions, the overflowing phenomenon does not occur any more but the very low volume of left-turning stream [SS] makes the 5 s opening offset irrelevant.

\subsubsection{Minor Road: Streams $E$ and $W$}

The opening offset $O(E) O(W)$ is depicted in Figure 6 . Whereas the CRONOS strategy produces a zero offset except for the three-stage regime $\mathrm{Cr}_{-} 3 \mathrm{st}(11 \%)$, the baseline strategy induces two contrasting regimes, with $\mathrm{W}$ opening $6 \mathrm{~s}$ before $\mathrm{E}$ under regime Ba_S1 preponderant in peak conditions, and the other way around under $\mathrm{Ba} \_0$ regime and fluid traffic conditions. This offset accounts for the benefits achieved with the CRONOS strategy for stream $\mathrm{E}$ in peak hour condition and for stream $\mathrm{W}$ in fluid traffic condition. The reasons why the baseline strategy does not perform better than the CRONOS strategy in the other two cases (E, fluid) and (W, peak) are now analyzed.

Contrary to what happens in the case of the main road, the inner storage zones $\mathrm{n}$ and $\mathrm{s}$ are supplied by two successive sources. Before the left-turning movements coming from the opposite input stream, a part of the upstream storage turns left: $100 \%$ of storage e supplies n, about $45 \%$ of storage w supplies s. The offsets $O(e) C(n)$ and $O(w) C(s)$ correspond to the time available to the turning upstream storage to clear (see Figure 7). Whereas the baseline strategy operates with a fixed $8 \mathrm{~s}$ $O(e) C(n)$ offset, the CRONOS strategy increases the offset to $14 \mathrm{~s}$ in about $30 \%$ of the cases (regimes Cr_S1, Cr_3st and Cr_AR1). This large offset is linked to the storage volume on zone e: when there are vehicles stored in zone e, the CRONOS strategy tends to increase the time for them to clear. The baseline strategy produces mean cycle duration around $10 \mathrm{~s}$ higher 
Table 3: Regimes of $\mathcal{E}$-phases sequences with predominant transitions.

\begin{tabular}{|c|c|c|c|c|c|c|c|c|c|}
\hline $\begin{array}{l}\text { Regime } \\
\text { name }\end{array}$ & $\begin{array}{l}\text { Share of all traf- } \\
\text { fic conditions } \\
(\mathrm{P} ; \mathrm{F})\end{array}$ & \multicolumn{8}{|c|}{$\begin{array}{l}\text { Sequences of } \mathcal{E} \text {-phases and predominant transitions (from left to right), } \\
\text { with duration in seconds (median and interquartile range) }\end{array}$} \\
\hline \multicolumn{10}{|c|}{ Baseline strategy } \\
\hline Ba_0 & $\begin{array}{l}62 \% \\
(34 \% ; 87 \%)\end{array}$ & $\Phi_{1}$ & &.- & $\begin{array}{l}\mathrm{E} \\
5 \\
{[2 ; 6]}\end{array}$ & $\Phi_{2}$ & $\begin{array}{l}\text { W } \\
5 \\
{[5 ; 5]}\end{array}$ & . & $\begin{array}{l}\mathrm{N} \\
5 \\
{[5 ; 5]}\end{array}$ \\
\hline Ba_S1 & $\begin{array}{l}38 \% \\
(66 \% ; 13 \%)\end{array}$ & $\Phi_{1}$ & $\begin{array}{l}\mathbf{S} \\
13 \\
{[10 ; 14]}\end{array}$ & . & $\begin{array}{l}\text { W } \\
6 \\
{[3 ; 7]}\end{array}$ & $\Phi_{2}$ & $\begin{array}{l}\mathrm{W} \\
5 \\
{[2 ; 5]}\end{array}$ & . & $\begin{array}{l}\mathrm{N} \\
5 \\
{[2 ; 5]}\end{array}$ \\
\hline \multicolumn{10}{|c|}{ CRONOS strategy } \\
\hline Cr_0 & $\begin{array}{l}40 \% \\
(31 \% ; 48 \%)\end{array}$ & $\overline{\Phi_{1}}$ & &.-- & & $\Phi_{2}$ & &.-- & \\
\hline $\mathrm{Cr} \_\mathrm{AR} 2$ & $\begin{array}{l}15 \% \\
(15 \% ; 15 \%)\end{array}$ & $\Phi_{1}$ & & -.- & & $\Phi_{2}$ & - & $\begin{array}{l}\varnothing \\
8 \\
{[6 ; 12]}\end{array}$ & - \\
\hline $\mathrm{Cr}_{-} \mathrm{S} 2$ & $\begin{array}{l}14 \% \\
(22 \% ; 8 \%)\end{array}$ & $\Phi_{1}$ & &.-- & & $\Phi_{2}$ & &.- & $\begin{array}{l}\mathbf{S} \\
14 \\
{[10 ; 16]}\end{array}$ \\
\hline $\mathrm{Cr}_{-} \mathrm{S} 1$ & $\begin{array}{l}12 \% \\
(15 \% ; 9 \%)\end{array}$ & $\Phi_{1}$ & $\begin{array}{l}\mathbf{S} \\
14 \\
{[10 ; 20]}\end{array}$ & .- & & $\Phi_{2}$ & &.-- & \\
\hline Cr_3st & $\begin{array}{l}11 \% \\
(10 \% ; 13 \%)\end{array}$ & $\Phi_{1}$ & &.- & $\begin{array}{l}\mathbf{E} \\
12 \\
{[10 ; 16]}\end{array}$ & - & $\begin{array}{l}\mathbf{W} \\
12 \\
{[10 ; 14]}\end{array}$ & .- & \\
\hline $\mathrm{Cr} \_\mathrm{AR} 1$ & $\begin{array}{l}7 \% \\
(7 \% ; 7 \%)\end{array}$ & $\Phi_{1}$ & - & $\begin{array}{l}0 \\
14 \\
{[6 ; 16]}\end{array}$ & - & $\Phi_{2}$ & & -.- & \\
\hline
\end{tabular}

Possible $\mathcal{E}$-phases $\quad \Phi_{1}(\mathrm{~N}+\mathrm{S}), \Phi_{2}(\mathrm{E}+\mathrm{W}), \mathrm{N}, \mathrm{S}, \mathrm{E}, \mathrm{W}, \mathrm{AR}$ (all red entry)

A Full $\mathcal{E}$-phase (median $>=12 s$ )

A Transition $\mathcal{E}$-phase $(12 s>$ median $\geq 5 s)$

- Short transition $\mathcal{E}$-phase (median $<5 s$ )

$\oslash \quad$ Long all red transition $\mathcal{E}$-phase (higher than $6 \mathrm{~s}$ for $75 \%$ samples)

. Short all red transition $\mathcal{E}$-phase (lower than $8 \mathrm{~s}$ for $100 \%$ samples)

than the CRONOS strategy whatever the traffic condition (Boillot et al., 2006), which induces higher storage volumes per cycle. It follows that during many cycles in peak hour conditions, the whole volume stored on zone e cannot clear the intersection and a few vehicles remain caught behind signal $\mathrm{n}$. Stream
$\mathrm{W}$ is prevented from producing unexposed flow. As for stream $\mathrm{E}$, offset $O(w) C(s)$ is very short for both strategies except for CRONOS Cr_AR1 regime (7\%). However, the hourly turning storage on zone w, which corresponds to stream [NN], keeps the same volume in fluid and peak conditions. The higher mean 
Table 5: Differences between CRONOS and the baseline strategy.

For each compared measure $m$, the absolute difference is computed as $\left(m_{C R O N O S}-m_{\text {baseline }}\right)$ and the relative difference as the absolute difference divided by $m_{\text {baseline }}$ * denotes non-significant differences $(p \geq 0.10)$. A percentage means that the difference is significant, with $p<0.05$ if bold or $p<0.10$ otherwise.

\begin{tabular}{|c|c|c|c|c|c|c|c|c|c|}
\hline & & $\mathrm{S}$ & $\mathrm{N}$ & $\mathrm{E}$ & $\mathrm{W}$ & $\mathrm{S}$ & $\mathrm{n}$ & $\mathrm{e}$ & W \\
\hline \multirow[t]{3}{*}{$V$} & $\mathrm{P}$ & $*$ & $*$ & $*$ & $*$ & $*$ & & $-4 \%$ & $*$ \\
\hline & & & & & & & -48 veh & -22 veh & \\
\hline & $\mathrm{F}$ & $*$ & $*$ & $*$ & $*$ & $*$ & $*$ & $*$ & $*$ \\
\hline \multirow[t]{2}{*}{$Z$} & $\mathrm{P}$ & $*$ & $*$ & $\begin{array}{l}-14 \% \\
-1 ' 29 '\end{array}$ & $*$ & $*$ & $*$ & $*$ & $*$ \\
\hline & $\mathrm{F}$ & $*$ & $*$ & $*$ & * & $*$ & $*$ & $\begin{array}{l}+23 \% \\
+2 ’ 04 ’\end{array}$ & * \\
\hline \multirow[t]{3}{*}{$Z_{V}$} & $\mathrm{P}$ & $*$ & * & $-9 \%$ & $*$ & $-5 \%$ & $*$ & $+14 \%$ & $*$ \\
\hline & & & & -0’57'” & & $-1 ' 14 ”$ & & +1'58' & \\
\hline & $\mathrm{F}$ & $*$ & * & $*$ & $*$ & $*$ & $\begin{array}{l}+6 \% \\
+0^{\prime} 45^{\prime}\end{array}$ & $\begin{array}{l}+28 \% \\
+2333^{\prime}\end{array}$ & * \\
\hline \multirow[t]{2}{*}{$Y$} & $\mathrm{P}$ & $\begin{array}{l}-18 \% \\
-2 ’ 38 ’\end{array}$ & $*$ & $\begin{array}{l}-40 \% \\
-2 ’ 27 ’\end{array}$ & $*$ & $*$ & $*$ & $*$ & $*$ \\
\hline & $\mathrm{F}$ & $*$ & * & $*$ & $\begin{array}{l}-22 \% \\
-0 ' 34 '\end{array}$ & $*$ & $\begin{array}{l}+16 \% \\
+0 ’ 36 ”\end{array}$ & $*$ & * \\
\hline \multirow[t]{2}{*}{$Y_{V}$} & $\mathrm{P}$ & $\begin{array}{l}-19 \% \\
-2 ’ 48 ’\end{array}$ & $*$ & $\begin{array}{l}-36 \% \\
-2 ' 12 ',\end{array}$ & $*$ & $\begin{array}{l}-8 \% \\
-1 ' 29 "\end{array}$ & $*$ & $*$ & $*$ \\
\hline & $\mathrm{F}$ & $\begin{array}{l}-23 \% \\
-1 ' 58 '\end{array}$ & $*$ & $*$ & $\begin{array}{l}-24 \% \\
-0 ’ 38 ’\end{array}$ & $\begin{array}{l}-15 \% \\
-1 ' 07 ’\end{array}$ & $\begin{array}{l}+20 \% \\
+0 ' 43 \%\end{array}$ & $\begin{array}{l}+13 \% \\
+0 ' 52 "\end{array}$ & * \\
\hline \multirow[t]{2}{*}{$Y / Z$} & $\mathrm{P}$ & $-10 \%$ & $*$ & $-18 \%$ & $+4 \%$ & $*$ & $*$ & $-6 \%$ & $*$ \\
\hline & $\mathrm{F}$ & $-14 \%$ & * & $-7 \%$ & $-15 \%$ & $-6 \%$ & * & $-9 \%$ & $-7 \%$ \\
\hline \multirow[t]{2}{*}{$X_{V}$} & $\mathrm{P}$ & $\begin{array}{l}+29 \% \\
+1 ' 54 "\end{array}$ & $*$ & $\begin{array}{l}+32 \% \\
+1 ' 15 '\end{array}$ & $*$ & $*$ & $*$ & $\begin{array}{l}+43 \% \\
+1 ' 18 '\end{array}$ & $*$ \\
\hline & $\mathrm{F}$ & $\begin{array}{l}+42 \% \\
+1 ' 28 '\end{array}$ & * & * & $\begin{array}{l}\mathbf{+ 5 0 \%} \\
+\mathbf{0} 25 \%\end{array}$ & $*$ & * & $\begin{array}{l}+68 \% \\
+1 ' 40 "\end{array}$ & $\begin{array}{l}+21 \% \\
+0 ' 22 \text { ' }\end{array}$ \\
\hline \multirow[t]{2}{*}{$Y_{m}$} & $\mathrm{P}$ & $\begin{array}{l}-29 \% \\
-2 ' 39 "\end{array}$ & $*$ & $*$ & $*$ & $*$ & $*$ & $*$ & $*$ \\
\hline & $\mathrm{F}$ & $\begin{array}{l}-27 \% \\
-1 ' 34 "\end{array}$ & $*$ & $*$ & $*$ & $*$ & $\begin{array}{l}+38 \% \\
+0 ’ 11 "\end{array}$ & $*$ & * \\
\hline
\end{tabular}

cycle duration for the baseline strategy increases the proportion of cycles with a non-zero turning volume on zone w. Stream E propensity to produce unexposed flow is limited, especially in fluid traffic conditions.

\subsection{Inner Streams}

The case of inner streams differs from entry streams to produce unexposed flow at the beginning of a green period as i) inner storage zones may be only partly filled up at the green onset, ii) after storage clearance, supplying the inner zone again may take some time depending on the signal opening offsets and iii) cross-traffic entry approaches are likely to get rapidly supplied at the red onset. The time during which an entry link remains empty after the red onset mainly depends on the traffic volume coming from the neighbouring intersections. It also depends on the control strategy and its commutation decisions, which may have a particular impact in the case of the vehicleactuated baseline strategy. In a previous publication (Boillot et al., 2006), we defined the "red but nobody" period per cycle as the number of seconds in a cycle between the red onset and the presence of the first vehicle on the entry link, as detected by the video sensor. We showed that the hourly "red but nobody" duration summed over the four entry links is higher for the CRONOS strategy (see Table 6).

The mean "red but nobody" period for streams $\mathrm{n}$ and $\mathrm{s}$ is high on their cross-traffic links, but producing unexposed flow also requires that these streams are ready to flow at the green onset. The probability of these inner zones not being empty at the end of the red period is higher with the baseline strategy. Indeed, the whole flow volume $[\mathrm{ES}]$ (resp. $([\mathrm{WN}]+[\mathrm{NN}])]$ always gets caught behind signal $\mathrm{n}$ (resp. signal $\mathrm{s}$ ) during the red period, which is not the case with regime $\mathrm{Cr}_{-} 3$ st of the CRONOS strategy. The higher mean cycle duration for the baseline strategy induces higher storage volumes. After storage clearance at the green onset, the storage zone is supplied again by the direct upstream entry, after a time gap that depends on the opening offset between the two signals (see the opening offsets $O(n) O(N)$ and $O(s) O(S)$ in Figure 8). 


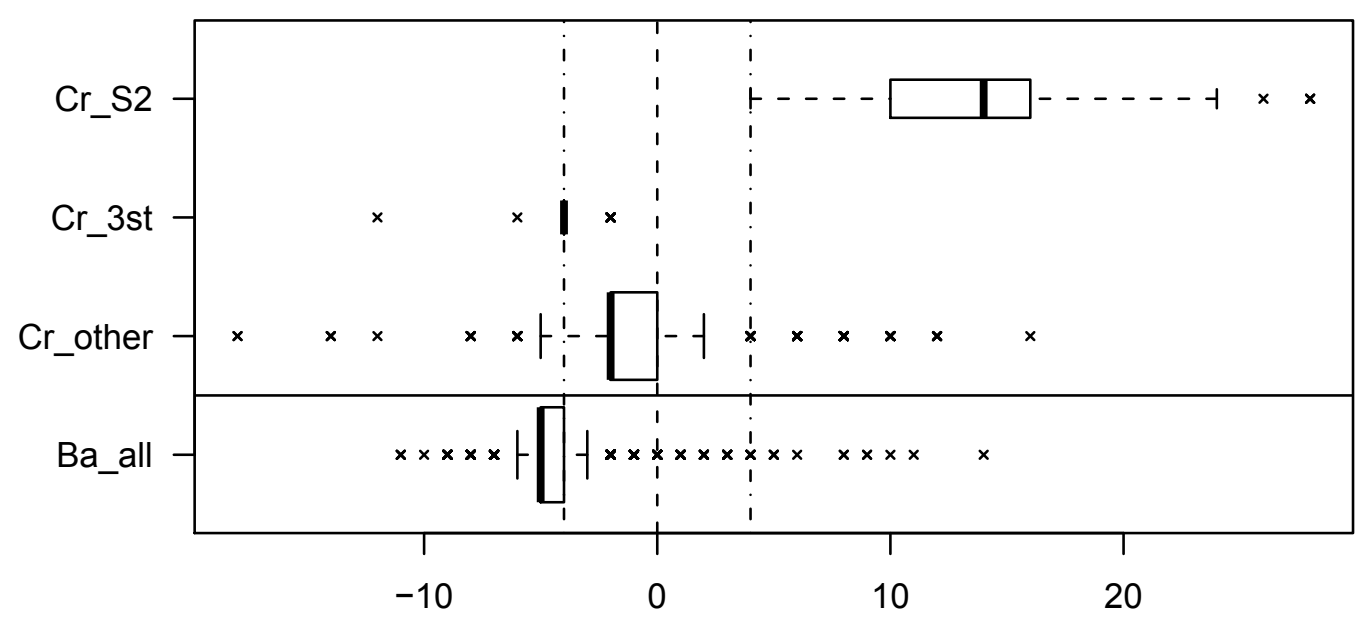

Figure 5: Boxplot of the offset $O(S) O(N)$ distribution (in seconds).

The box widths are proportional to the square-roots of the number of observations. The whiskers extend to the most extreme point which is no more than 1.5 times the interquartile range from the box.

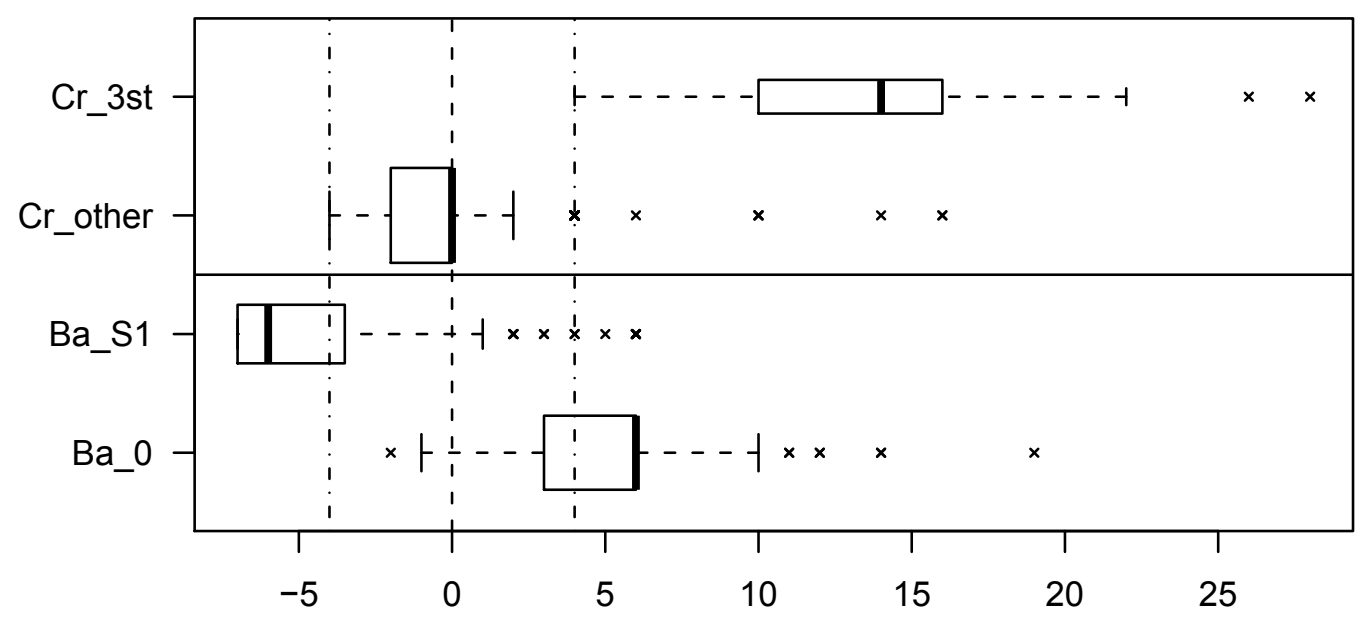

Figure 6: Boxplot of the offset $O(E) O(W)$ distribution (in seconds).

The box widths are proportional to the square-roots of the number of observations. The whiskers extend to the most extreme point which is no more than 1.5 times the interquartile range from the box.

Whereas signal $\mathrm{N}$ opens before signal $\mathrm{n}$ in three quarters of the cases with the baseline strategy, it never happens with the CRONOS strategy. Under regimes Cr_AR2 and Cr_S2 (30\% of all cycles) signal $\mathrm{N}$ opens more than $10 \mathrm{~s}$ after signal $\mathrm{n}$ in three quarters of the cases; there is a large time gap during which the volume clearing signal $\mathrm{n}$ is likely to be very low or null. This leads to a production of exposed flow which is slightly but sig- nificantly higher for the CRONOS strategy in fluid conditions. The situation is the contrary for stream s: with the baseline strategy signal, $\mathrm{S}$ opens mostly more than $8 \mathrm{~s}$ after signal $\mathrm{s}$, whereas the offset is $5 \mathrm{~s}$ shorter (difference in median) with the CRONOS strategy. Being supplied quite late by the large volume entry flow $\mathrm{S}$ with the baseline strategy, inner stream s does not flow during the "red but nobody" period of cross-traffic en- 

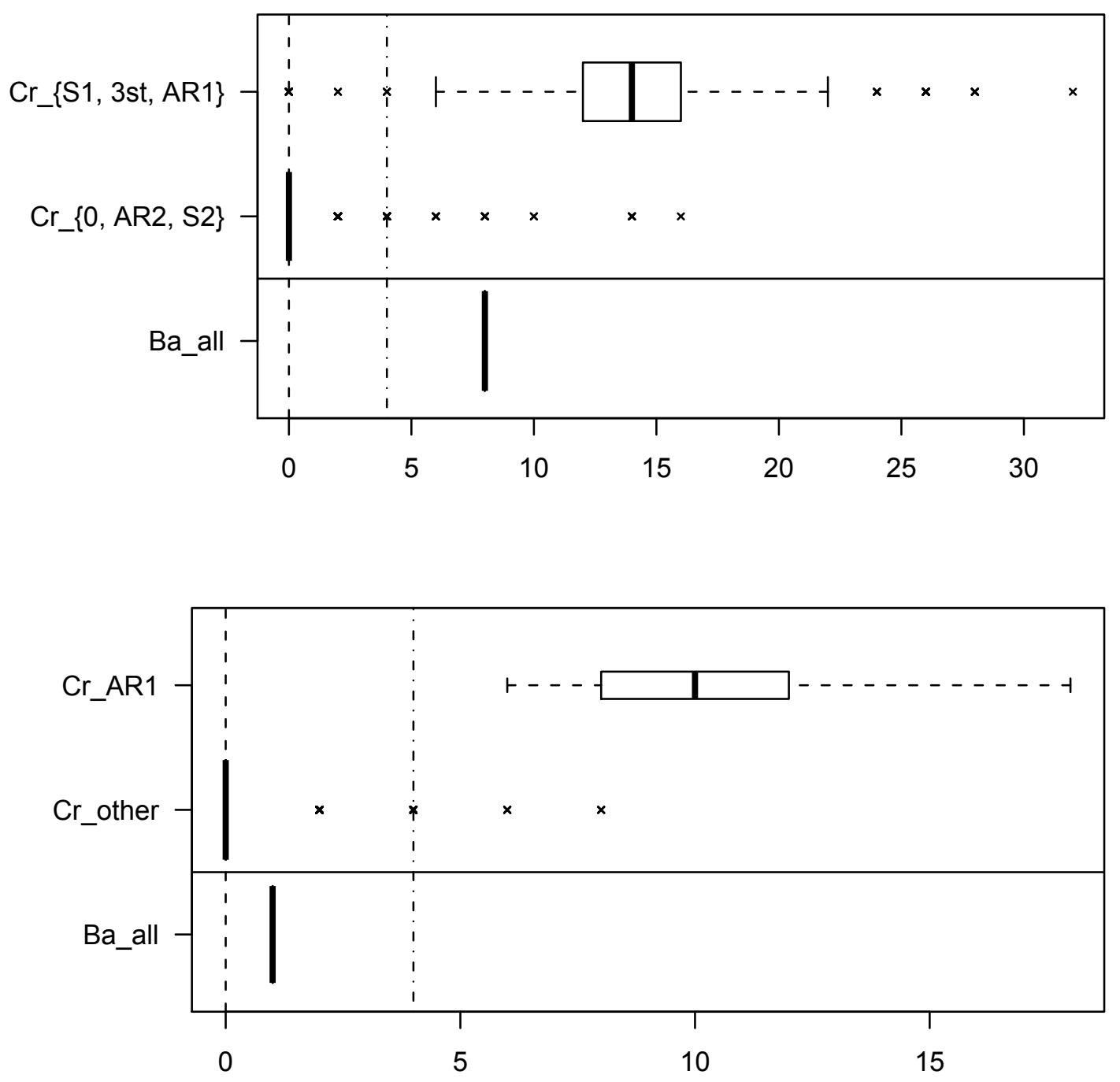

Figure 7: Boxplot of the distributions of the offsets $O(e) C(n)$ (top) and $O(w) C(s)$ (bottom) (in seconds).

The box widths are proportional to the square-roots of the number of observations. The whiskers extend to the most extreme point which is no more than 1.5 times the interquartile range from the box.

Table 6: The "red but nobody" mean period per cycle (in seconds).

\begin{tabular}{lllllllll}
\hline & $\begin{array}{l}\text { Inner stream s } \\
\text { (opp. }\end{array}$ entry E) & \multicolumn{2}{c}{$\begin{array}{l}\text { Inner stream n } \\
\text { (opp. entry W) }\end{array}$} & \multicolumn{2}{l}{$\begin{array}{l}\text { Inner stream e } \\
\text { (opp. entry N) }\end{array}$} & $\begin{array}{l}\text { Inner stream w } \\
\text { (opp. entry S) }\end{array}$ \\
\hline & bas. & CRO. & bas. & CRO. & bas. & CRO. & bas. & CRO. \\
\hline P & 6 & 5 & 13 & 14 & 4 & 6 & 2 & 2 \\
F & 14 & 13 & 19 & 19 & 4 & 7 & 3 & 4 \\
\hline
\end{tabular}

try link E and produces a higher level of exposed flow.

As for streams w and e, the "red but nobody" periods of the cross-traffic entry link are too short to enable substantial unexposed flow, especially for inner stream w. Even if the opening offset between $\mathrm{W}$ and $\mathrm{w}$ is also very short with the CRONOS strategy, the difference in exposed flow is small and not significant. The situation is more complex for stream e as the exposed flow difference reveals a small but significant increase for the CRONOS strategy. This result is difficult to interpret as stream e produces the highest difference in volume-normalized $Z_{V}$ du- 

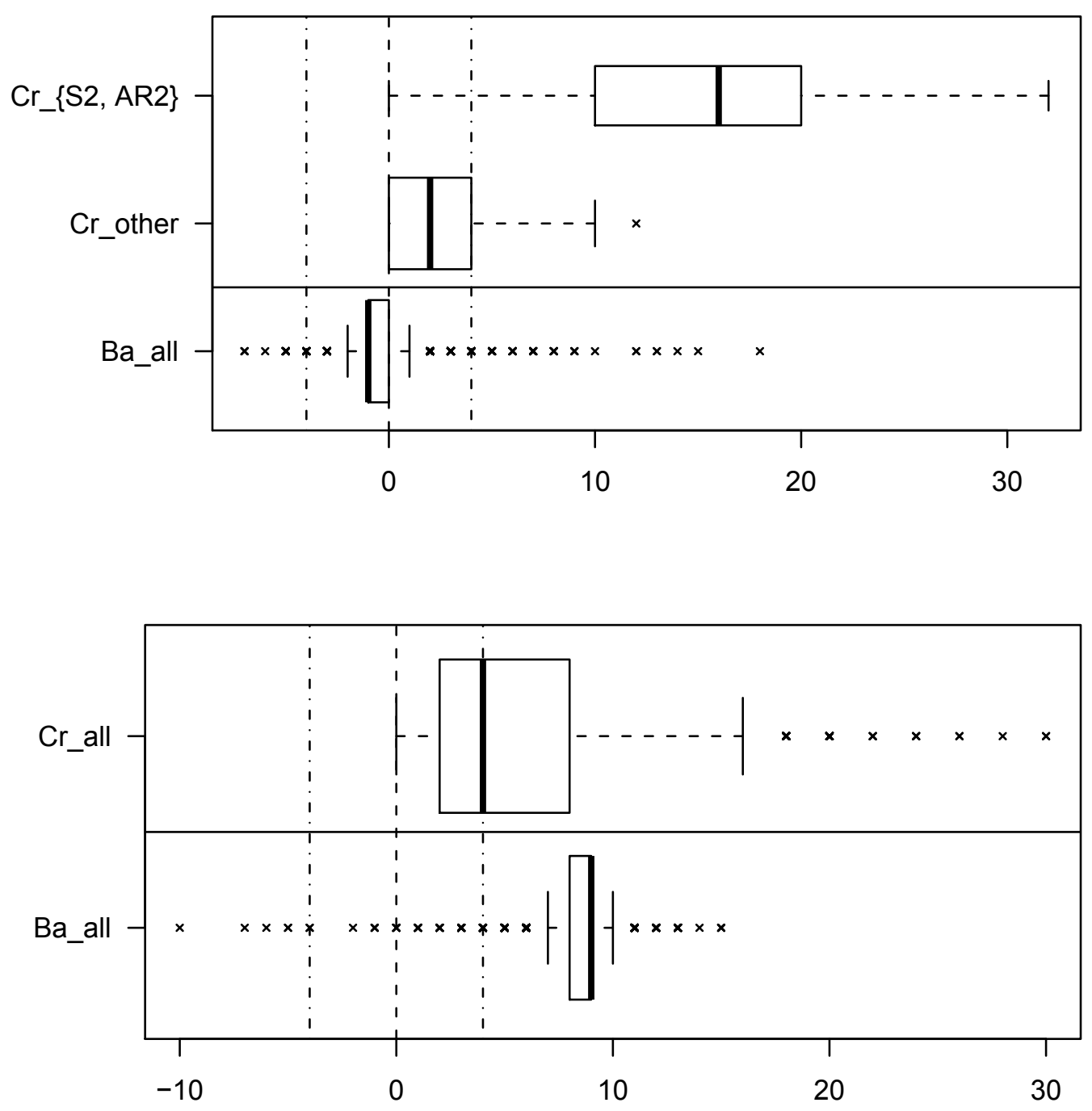

Figure 8: Boxplot of the distributions of the offset $O(n) O(N)$ (top) and $O(s) O(S)$ (bottom) (in seconds).

The box widths are proportional to the square-roots of the number of observations. The whiskers extend to the most extreme point which is no more than 1.5 times the interquartile range from the box.

ration. Moreover the conflict zone downstream signals e and $\mathrm{N}$ merges with storage zone $n$ because of the lack of outbound leg. Storage $\mathrm{n}$ spreads over the conflict zone and often overflows on storage zone e and the automatic detection system described in 4.1 has trouble discriminating between unexposed and exposed flows.

\section{Discussion}

On the studied intersection, a traffic control strategy may decrease the exposure of road users to lateral collision with road users from a cross-traffic stream. For entries, the key to decrease the exposure to lateral collision is to empty the inner storage zones and slow their replenishment. For inner streams, benefits are less frequent and more limited in scope because they require a low volume of the cross-traffic entry and enough volume quickly at the green onset for the inner stream.

\subsection{The Relationship to Safety}

Is it possible to conclude from a decrease in the measure of exposure $Y$ to an improvement in safety? Answering this question is difficult as safety depends not only on exposure, but also on its temporal distribution in the signal cycles. Two safetyrelated factors are indeed not evenly distributed in the signal cycles. First, even if the relationship is not well known (Hauer, 2009), speed contributes to the probability of getting involved 
in a collision, directly and indirectly through red-light running (Elmitiny et al., 2010). Speeds are low at the beginning of the green period, during queue discharge, and are higher at the end when traffic is free flowing. Speed information was not available in this experiment. Second, red-light running is a necessary condition for a lateral collision to occur between a road user crossing the conflict zone and another road user running the red light. These violations occur mainly at the beginning of the red period (Zimmerman and Bonneson, 2005), and less frequently as early starts at the end (Chiou and Chang, 2010).

There is no reason to think that the distribution of exposure within signal cycles is the same for the two control strategies. For example, the baseline strategy is vehicle-actuated while the CRONOS strategy is not, and this could increase the exposed flow at the end of the green period if vehicles arrive steadily, when there is likely to be vehicles in the cross-traffic storage zone. The exact relationship of speed, red-light running, exposure, its temporal distribution, and safety is not known at this point. For the rest of the discussion, we will assume that large enough decreases in the measured exposure $Y$ translate into decreases in the expected number of lateral collisions, i.e. safety improvements. In particular, statistically significant differences for entries amount to relative differences between $19 \%$ and $36 \%$ (see Table 5). Under this assumption, several recommendations are made in the next sub-section.

\subsection{Recommendations for Traffic Control Strategies}

Our definition of exposure to lateral collision can be applied to any kind of intersection. However, the results in terms of the comparison between the two strategies cannot be generalized easily. In particular, the analysis proposed in section 5 applies only to intersections with protected left-turn movements. The following reasons explain why the CRONOS strategy improves upon the baseline strategy:

- It has short cycles, so fewer road users are stopped in storage zones and there are more opportunities for "red but nobody" at the beginning of the red phase.

- Measuring road users' stops, including in the intersection inner area, makes it possible to manage and minimize the number of stopped road users.

- The opening and closing offsets for traffic signals are not imposed and fluctuate from cycle to cycle. These offsets often have bimodal distributions, one mode around zero, the other with very large offsets for specific regimes. In this way, the CRONOS strategy avoids unfavourable cases, like for example the increased exposed flow with the baseline strategy on the $\mathrm{S}$ entry, which is mostly caused by the 5 s opening offset $O(S) O(N)$.

These features are related to the high level of adaptiveness of the CRONOS strategy to traffic dynamics. As such, they would yield similar advantages in any intersection with protected leftturn movements, whether controlled in isolation or as part of a network. Even if favouring short cycles is a recommendation that can be followed whatever the type of control strategy, our results show that there are additional advantages for an adaptive strategy that focuses on the real-time optimization of delays using sensors that provide information about stops and queues.

Furthermore, the CRONOS strategy could be modified to take explicitly into account road users' exposure to lateral collisions. The CRONOS strategy estimates the near future signal states by optimizing a global criterion - the total delay in our experiment - while complying with safety constraints on signal state durations and correlations. Bus priority has been already implemented within this control strategy by adding constraints to extend the green duration in case of a bus arrival at a stop line or to switch as soon as possible to green in order to minimize bus delay. Similarly, real-time explicit constraints on the range of the switchovers (green and red onsets) can be added to the optimization done by the CRONOS strategy. An additional goal could be to maximize unexposed crossing of the conflict zone by monitoring the conflicting streams.

\section{Conclusion}

The real-time adaptive strategy CRONOS is compared to a baseline time plan strategy with vehicle-actuated ranges in terms of duration of exposure to lateral collision. The mean hourly durations for the two strategies are significantly different in various areas of the experimental intersection. In particular, the exposure in peak traffic conditions drops by roughly 5 min with the CRONOS strategy, mostly on the entry streams. The features of the CRONOS strategy responsible for these results come from its use of stop detection and its advanced level of adaptativeness to traffic. This supports the argument that such a strategy would reduce the exposure to lateral collision in most signalized intersections with protected left-turn movements. This paper opens perspectives for the inclusion of realtime safety constraints and objectives in adaptive strategies. Traditional exposure control, i.e. reducing motorized travel, is known to be a difficult strategy: this work shows that there are ways to control exposure to collision while meeting an equal amount of demand and reducing delays.

This study also deals with an original approach to study the exposure of road users to lateral collision in an intersection. Future work on that topic will rely on traffic monitoring techniques, in particular using video sensors, to obtain all road users' trajectories (Saunier and Sayed, 2006). Such microscopic data makes it possible to develop and automatically compute robust exposure and safety measures, such as the probability of collision and the time to collision (Saunier et al., 2010). The severity of all traffic interactions can be thus estimated to study their relationship to safety and analyze the whole continuum of interactions, from "normal" situations, typically used as exposure, to the most severe, conflicts and collisions, typically used as safety indicators. This will help to design better surrogate safety measures and to better understand collision processes. 


\section{Acknowledgment}

The authors wish to thank the reviewers for their constructive comments that helped to significantly improve the paper.

\section{References}

Amundsen, F., Hydén, C. (Eds.), 1977. Proceedings of the first workshop on traffic conflicts. Institute of Transport Economics, Oslo, Norway.

Archer, J., Dec. 2004. Methods for the assessment and prediction of traffic safety at urban intersections and their application in micro-simulation modelling. Academic thesis, Royal Institute of Technology, Stockholm, Sweden. URL http: //urn.kb.se/resolve?urn=urn:nbn: se : kth: diva-143

Ardekani, S., Hauer, E., Jamei, B., 2001. Traffic Flow Theory: A State-of-theArt Report. TRB Committee on Traffic Flow Theory \& Characteristics, Ch. Traffic Impact Models, pp. 232-257.

Aubert, D., Bouzar, S., Lenoir, F., Blosseville, J.-M., 1996. Automatic vehicle queue measurement at intersections using image-processing. In: $8^{\text {th }}$ International Conference on Road Traffic Monitoring \& Control. Vol. 422. London, pp. 100-104.

Boillot, F., Midenet, S., Pierrelée, J.-C., 2006. The real-time urban traffic control system cronos: Algorithm and experiments. Transportation Research Part C: Emerging Technologies 14 (1), 18-38.

Chapman, R., Jun. 1973. The concept of exposure. Accident Analysis \& Prevention 5 (2), 95-110.

Chin, H. C., Quddus, M. A., 2003. Applying the random effect negative binomial model to examine traffic accident occurrence at signalized intersections. Accident Analysis \& Prevention 35 (2), 253 - 259.

Chiou, Y.-C., Chang, C.-H., 2010. Driver responses to green and red vehicular signal countdown displays: Safety and efficiency aspects. Accident Analysis \& Prevention 42 (4), 1057-1065.

Elmitiny, N., Yan, X., Radwan, E., Russo, C., Nashar, D., 2010. Classification analysis of driver's stop/go decision and red-light running violation. Accident Analysis \& Prevention 42 (1), 101-111.

Elvik, R., Erke, A., Christensen, P., 2009. Elementary units of exposure. Transportation Research Record: Journal of the Transportation Research Board 2103, 25-31.

Greibe, P., 2003. Accident prediction models for urban roads. Accident Analysis \& Prevention 35, 273-285.

Hauer, E., 1995. On exposure and accident rate. Traffic Engineering + Control 36 (3), 134-138.

Hauer, E., 2009. Speed and safety. Transportation Research Record: Journal of the Transportation Research Board 2103, 10-17.

Hauer, E., Ng, J., Lovell, J., 1988. Estimation of safety at signalized intersections. Transportation Research Record: Journal of the Transportation Research Board 1185, 48-61.

Hydén, C., 1987. The development of a method for traffic safety evaluation: The swedish traffic conflicts technique. Ph.D. thesis, Lund University of Technology, Lund, Sweden, bulletin 70 .

Midenet, S., Jul. 2005. Impact of the signal control strategy on red light running. In: Workshop Safety and Context, Fifth International and Interdisciplinary Conference on Modeling and Using Context CONTEXT-05. Paris, France.

URL ftp: //ftp.informatik.rwth-aachen.de/pub/publications/ CEUR-WS/Vol-158.zip

Midenet, S., Boillot, F., Pierrelée, J.-C., 2004. Signalized intersection with realtime adaptative control: on-field assessment of $\mathrm{CO}_{2}$ and pollutant emission reduction. Transportation Research Part D: Transport and Environment 9, 29-47.

Mitra, S., Chin, H. C., Quddus, M., 2002. Study of intersection accidents by maneuver type. Transportation Research Record: Journal of the Transportation Research Board 1784, 43-50.

Qin, X., Ivan, J., Ravishanker, N., Liu, J., Tepas, D., 2006. Bayesian estimation of hourly exposure functions by crash type and time of day. Accident Analysis \& Prevention 38, 1071-1080.

Saunier, N., Midenet, S., 2010. Automatic Estimation of the Exposure to Lateral Collision in Signalized Intersections using Video Sensors. Tech. rep., arXiv.

URL http://arxiv.org/abs/1012.4776v1
Saunier, N., Sayed, T., Jun. 2006. A feature-based tracking algorithm for vehicles in intersections. In: Third Canadian Conference on Computer and Robot Vision. IEEE, Québec.

Saunier, N., Sayed, T., Ismail, K., 2010. Large scale automated analysis of vehicle interactions and collisions. Transportation Research Record: Journal of the Transportation Research Board 2147, 42-50.

Sayed, T., Zein, S., 1999. Traffic conflict standards for intersections. Transportation Planning and Technology 22, 309-323.

Sebastian, K., 1999. Collision analysis of left-turn maneuvers at signalized intersections. In: Transportation Research Board Annual Meeting Compendium of Papers. Washington, D.C.

Svensson, A., Hydén, C., Mar. 2006. Estimating the severity of safety related behaviour. Accident Analysis \& Prevention 38 (2), 379-385.

Transportation Research Board, 2000. Highway Capacity Manual (HCM 2000). National Academy of Sciences, Washington, D.C

Wang, X., Abdel-Aty, M., 2008. Analysis of left-turn crash injury severity by conflicting pattern using partial proportional odds models. Accident Analysis \& Prevention 40 (5), 1674-1682.

Zhang, C., Ivan, J., Jonsson, T., 2006. Predicting two-lane highway crashes using crash opportunities: A newly defined measure of exposure. In: Transportation Research Board Annual Meeting Compendium of Papers. Washington, DC.

Zimmerman, K., Bonneson, J., 2005. Investigation of time into red for red lightrelated crashes. Transportation Research Record: Journal of the Transportation Research Board 1922, 21-28. 